\title{
Contribuições de Paulo Freire para o Pensamento Educacional Latino-Americano
}

Neto, José Batista ${ }^{1}$

Santiago, Eliete ${ }^{2}$

\section{Resumo}

O presente artigo resulta de uma revisita a textos de Paulo de Freire incursionando por princípios, teses e práticas construídas em resposta às questões postas pela Educação. Abordamos quatro contribuições do que chamaremos as obras do pensamento de Freire, evidenciamos traços como a singularidade biográfica, a originalidade de sua construção teórica e o cultivo de uma profunda coerência entre vida e obra. Valemo-nos para, fundamentalmente, de alguns depoimentos de pesquisadores de orientação teórica crítica disponível como produção acadêmica e da sua obra do autor para evidenciar as contribuições freireanas para o pensamento da educação latino-americano.

Pedagogia freireana. Educação latino-americana. Obras de pensamento.

\section{Abstracto}

Este artículo resulta de una nueva visita a los textos de Paulo Freire incursionando por principios, tesis y prácticas construidas en respuesta a las preguntas formuladas por la educación. Abordamos cuatro contribuciones que llamaremos de las obras de pensamiento de Freire, evidenciamos rasgos como la singularidad biográfica, la originalidad de su construcción teórica y el cultivo de una profunda coherencia entre la vida y la obra. Hemos utilizado fundamentalmente algunos testimonios de investigadores de orientación teórica crítica disponible tal como producción académica y de su obra al respecto del autor para poner de relieve las contribuciones freireanas al pensamiento de la educación en Latinoamerica.

Pedagogía freireana. Educación latinoamericana. Obras de pensamiento.

\footnotetext{
1 Doutor em Ciências da Educação, Professor Associado do Departamento de Métodos e Técnicas de Ensino do Centro de Educação da UFPE, membro da Cátedra Paulo Freire da UFPE. E-mail: josebn@uol.com.br

2 Doutora em Ciências da Educação, Professora Titular do Departamento de Administração Escolar e Planejamento Educacional do Centro de Educação da UFPE, Coordenadora da Cátedra Paulo Freire da UFPE. E-mail: mesantiago@uol.com.br
} 


\section{Introdução}

Em definitivo, Paulo Freire ofereceu muitas contribuições à educação para - Brasil, para a América Latina e para o mundo. São tantas que não constitui tarefa fácil selecionar algumas que, por sua significação e relevância, possam compor este breve espaço tempo. Selecionar nunca é tarefa fácil, salvo quando se quer esquecer, silenciar. Não é o caso. Dispusemo-nos a rememorar, revisitar, restituir ideias, princípios, teses construídas em resposta às questões postas pela Educação. Assim, arbitrariamente, identificamos quatro contribuições do que chamaremos as obras do pensamento de Freire, a que nos dedicaremos nesse breve texto.

Entendemos por obra de pensamento um trabalho de reflexão sobre eventos inscritos na experiência singular dos sujeitos. Ela surge a partir das concepções originais de um sujeito, germinando de sua história de vida, como adverte Dominique Maingueneau:

As obras emergem em percursos biográficos singulares, porém esses percursos definem e pressupõem um estado determinado do campo. (...) $\mathrm{O}$ ato de escrever, de trabalhar num manuscrito, constitui a zona de contato mais evidente entre a 'vida' e a 'obra'. Trata-se de fato de uma atividade inscrita na existência, como qualquer outra, mas que também se encontra na órbita de uma obra, na medida daquilo que assim a fez nascer. (MAINGUENEAU, 1995, p.45)

Ora, se as obras "emergem em percursos biográficos singulares", no que concerne ao educador pernambucano, alvo dessas observações, constatamos não só a singularidade em sua biografia, mas a originalidade de sua construção teórica e o cultivo de uma profunda coerência entre vida e obra. A justo título, coerência é uma das marcas de uma trajetória de vida, cuja admiração de muitos intelectuais e povos deu a volta ao mundo. Nessa perspectiva, apresentamos depoimentos de educadores de orientação teórica crítica, reunidos por Ruth Pavan em seu estudo sobre a presença de Paulo Freire nos trabalhos do GT Educação Popular da Anped (2008).

A justo título, Pavan diz das muitas aprendizagens que Michel Apple (2006) realizou com Freire em matéria de educação.

Meu trabalho intenso com os ativistas brasileiros, e o que aprendi com eles, começou no meio da década de 1980, logo 
depois que se extinguiu o governo militar apoiado pelos Estados Unidos. Esse trabalho continuou por meio da intensa interação que tive com Paulo Freire e tornou-se ainda mais intenso, pois ajudei o Partido dos Trabalhadores - e com eles aprendi - a construir uma educação digna no Brasil. (APPLE, 2006, p.13, citado por PAVAN, 2008, p.2).

Peter McLaren, por sua parte, afirma que:

Freire não só representa um revolucionário em educação comprometido com a libertação dos oprimidos, com a luta pela justiça social e a transformação da educação, mas sua pedagogia adquiriu um status legendário. Sua pedagogia "começou como um meio de conferir poder a oprimidos camponeses brasileiros, atingiu um status legendário através dos anos. Poucos educadores caminham tão sabiamente e com tanta determinação entre as fronteiras da linguagem e da cultura." (MCLAREN, 1997, p.327, citado por PAVAN, 2008, p.2).

Henri Giroux reconhece em Freire características que o fazem não apenas um homem de seu tempo, mas também do tempo futuro. Como educador da esperança que é, construiu um discurso, uma prática e uma concepção de educação e de vida que

[...] representam um modo de reconhecer e criticar um mundo que vive perigosamente à beira da destruição. [...] A obra e presença de Freire estão aí não apenas para nos lembrar o que somos, mas também para sugerir no que podemos nos transformar. (GIROUX, 1997, p.156, citado por PAVAN, 2008, p.2)

\section{Paulo Freire: um dos pais da Teoria Crítica em Educação}

Estudiosos brasileiros das tendências do pensamento pedagógico, a exemplo de Saviani, Libâneo, Gadotti e tantos outros, são unânimes em reconhecer o papel pioneiro de Freire na construção da Teoria Crítica em Educação.

Do mesmo modo, Giroux (1997) lembra que ele muito contribuiu para a pedagogia crítica: "[...] a obra de Freire oferece uma visão de pedagogia e práxis que é partidária em sua essência; em sua origem e intenções, ela é a favor de 'optar pela vida"' (GIROUX, 1997, p.56). 
Sua filiação às correntes críticas do pensamento pedagógico se estabelece desde sua primeira obra, Educação e atualidade brasileira ${ }^{3}$. Ali, um problema para Freire era, nos termos de então, a relação entre a educação e os problemas da época, entre educação e contexto sócio político em que ela se insere. Isso o faz, anos depois, afirmar em um documentário de título evocativo Paulo Freire Contemporâneo: "O que eu já buscava naquela época [anos 50/60] era uma crítica à educação brasileira."

Em Educação e atualidade brasileira, Freire dialoga com autores nacionais de diferentes orientações teóricas, desde isebianos ${ }^{4}$, como Guerreiro Ramos, Álvaro Vieira Pinto, Roland Corbisier, até estudiosos considerados como "explicadores do Brasil", a exemplo de Gilberto Freyre e Caio Prado Jr., mas também com Anísio Teixeira e Fernando Azevedo. É possível identificar dois elementos que unem esses autores: priorizam a leitura histórica da realidade brasileira e veem na educação um meio de promoção do desenvolvimento.

As análises de Freire nessa obra o fazem aproximar-se das teses de Anísio Teixeira sobre o crescimento industrial que vive o Brasil a partir dos anos 1950, em especial durante o período de Juscelino Kubistchek. Embora seja um entusiasta da industrialização, traço que envolve os intelectuais desse período, preocupa-o que a modernização de nossa formação social não tenha sido acompanhada por igual avanço democrático. Percebe que conhecemos dificuldades para que a participação se faça na construção das decisões políticas e públicas, em função da "inexperiência democrática" que resulta de um passado colonial restrito, daí porque o espirito democrático não teria vingado no país. No entanto, reconhece as contradições manifestas num tempo

\footnotetext{
${ }^{3}$ Educação e atualidade brasileira originalmente é a tese de Paulo Freire escrita em 1959. Foi concebida com a finalidade de atender às exigências do concurso para efetivação como professor da cadeira de História e Filosofia da Educação na Escola de Belas Artes da Universidade do Recife.

${ }^{4}$ Em referência ao Instituto Superior de Estudos Brasileiros (ISEB), criado em 1955 e extinto em 1964 pelo regime militar. Era vinculado ao Ministério de Educação e Cultura, dotado de autonomia administrativa, com liberdade de pesquisa, de opinião e de cátedra. Realizou pesquisa e ensino de problemas brasileiros nos campos das Ciências Sociais e Humanas, com foco na temática do desenvolvimento, tendo sido uma das instituições responsáveis por elaborar e irradiar as teses do nacionaldesenvolvimentismo.
} 
de transformações que podem, de resto, interferir na mentalidade antidemocrática arraigada no espírito do brasileiro.

Por outro lado, seu otimismo o faz crer, como Anísio Teixeira, na possibilidade de formar no brasileiro/a hábitos e disposições democráticas por meio de processos educativos escolares. Essa tese colocará a escola no centro do debate sobre a democratização da sociedade brasileira, no qual desempenhará papel fundamental. No fundo, firma-se a ideia de que a democracia como uma experiência humana para ser vivida, precisa ser aprendida. Não que ela ocorra nessa ordem, pois se pode aprendê-la vivendo-a e vivendo-a aprendê-la. Eis aqui um legado de Freire para as sociedades, a não separação entre o vivido e o pensado, entre a educação e compromisso político, entre o intelectual e as transformações de seu tempo.

Esse é o primeiro texto de maior fôlego que produzirá; texto que tem por base as experiências educacionais vividas no SESI desde os anos 1940.

Vinte e dois anos depois, Freire profere a Conferência de abertura do Congresso Brasileiro de Leitura, na qual toma a leitura como objeto desde uma perspectiva crítica, como só o é de ser. Ali reafirma uma compreensão que se difundirá como algumas das tantas que ouvimos e lemos toda vez que se pretendeu e pretende citá-lo em algum material escrito (texto acadêmico, texto político, epígrafe, panfleto, etc.). Diz Freire que a "compreensão crítica do ato de ler não se esgota na decodificação pura da palavra escrita ou da linguagem escrita, mas que se antecipa e se alonga na inteligência do mundo. A leitura do mundo precede a leitura da palavra..." (1982, p.11) (grifos nossos). Sem esquecer que o trecho selecionado evidenciava antecipações de uma das ideias de base do que mais tarde se denominou de letramento, chama a atenção, nos comentários que em geral se seguem, a maior importância que se atribui ao entendimento do mundo, do outro e de si, que a leitura pode trazer. Igualmente, causa perplexidade a oposição que, por vezes, se enxerga entre uma leitura e outra. Tão importante quanto o trecho citado é o que o precede e o que está posto na sequência. A leitura é obra da inteligência e pode expandila, na medida em que é feita de forma crítica. Esta parece ser uma primeira ideia importante a ser extraída. Por outro lado, no entender de Freire, a leitura 
do mundo não prescinde da leitura da palavra, portanto, uma existe com e pela outra. Uma relação de implicação está na base da leitura e explicita seu dinamismo e os vínculos entre texto e contexto. A compreensão de texto implica a percepção das relações que constituem o mundo a que o escrito alude e representa.

\section{Lições do exílio}

A ruptura da institucionalidade provocada pelo golpe militar de 1964, faz com que Freire e sua família viva a amarga experiência do exílio. A experiência do exílio começou sozinho (sem passaporte e sem família), mas não solitário.

Ninguém chega a parte alguma só, muito menos ao exílio... Carregamos a memória de muitas tramas, o corpo molhado de nossa história, de nossa cultura; a memória, às vezes nítida, clara, de ruas de infância, da adolescência ... uma frase possivelmente já olvidada por quem a disse. Uma palavra por tanto tempo ensaiada e jamais dita, afogada sempre na inibição, no medo de ser recusado, que, implicando a falta de confiança em nós mesmos, significa também a negação do risco (FREIRE, 1992, p.32-3).

Primeiro na Bolívia (quase 60 dias, entre outubro e novembro de 1964), depois no Chile durante a presidência do democrata cristão Eduardo Frei e do socialista Salvador Allende. Outro exílio mais com o golpe chileno comandado por Pinochet. Encerra sua vida no Chile em abril de 1969 e, a convite da Universidade de Harvard (Massachussetts), vai viver no EUA, onde permaneceu por quase um ano como Professor Visitante. Daí parte para a Suíça, a convite do Conselho Mundial das Igrejas, fixou-se em Genebra, onde viveu por dez anos até retornar em definitivo para o Brasil em junho de 1980.

A experiência do exílio deixa marcas profundas, mas é também um tempo para que pudesse tomar distanciamento do Brasil e, assim, podê-lo ver melhor, em suas grandezas e mazelas. Quem se exila costuma idealizar o que vive fora ou que tinha antes em seu país. Sabe-se depois, a custa de muita reflexão sobre essa difícil experiência, que o exílio não é uma coisa nem outra. Ele é um momento de tomada de consciência das diferenças culturais, mas também de tomada consciência de sua própria identidade cultural. Tomada de consciência que possibilita a construção de um valor: o valor que advém da cultura de 
origem. Permite também a ruptura com a visão colonial/colonizada, aquela que se designa pela máxima o melhor é o que vem de fora.

A experiência do exílio (contexto de empréstimo, como dizia) é motivo de aprendizagens para Freire, que a expressou nesses termos:

E o exílio então me deu essa outra grande lição. Na medida em que tu te experimentaste no teu contexto, historicamente, socialmente, na medida em que tuas raízes entrarem nesse contexto, em primeiro lugar nunca mais deixas de pertencer a esse contexto e em segundo lugar jamais pertences só a ele. Eu sinto em mim um pedaço da raiz ultrapassando o meu sapato onde quer que eu esteja. Essa fala arrastada, do nordestino que continua, o gosto da comida, a minha visão de mundo, a minha linguagem. (FREIRE. In ARAÚJO FREIRE, 2006, p.206).

\subsection{Leitura do mundo como princípio educativo}

Outra contribuição ainda aponta para a importância de irmos cavoucar em nossa própria experiência, em nossa história de vida. Assim, nesse mesmo texto sobre $A$ importância do ato de ler, deixam evidentes os saberes que somos capazes de construir quando nos dispomos a ler e "reler" momentos vividos, guardados na memória. Saberes construídos ao longo de nossa vida e que vão nos constituindo. A isso que, hoje, chamamos de saberes experienciais, acreditando-se, por vezes, ser achado recente e de origem exógena, Freire preferia denominar de saber da experiência feito.

A retomada da infância distante, buscando a compreensão do meu ato de "ler" o mundo particular em que me movia - e até onde não sou traído pela memória -, me é absolutamente significativa. Nesse esforço a que me vou entregando, re-crio, e re-vivo, no texto que escrevo, a experiência vivida no momento em que ainda não lia a palavra (1982, p.12).

Não lia palavra, mas era capaz de ir, pouco a pouco, a medida que as experiências se sucediam, lendo o mundo, o seu mundo. A esse ato de ler que não consiste em ruptura com a "leitura" do mundo, chamou de leitura da "palavramundo".

A velha casa, seus quartos, seu corredor, seu sótão, seu terraço - o sítio das avencas de minha mãe -, o quintal amplo em que se achava, tudo isso foi o meu primeiro mundo. [...] Os 


\begin{abstract}
"textos", as "palavras", as "letras" daquele contexto se encarnavam [...] na tonalidade diferente de cores de um mesmo fruto em momentos distintos: o verde da mangaespada verde, o verde da manga-espada inchada; o amarelo esverdeado da mesma manga amadurecendo, as pintas negras da manga mais além de madura. A relação entre essas cores, o desenvolvimento do fruto, a sua resistência à nossa manipulação e o seu gosto. Foi nesse tempo, possivelmente, que eu, fazendo e vendo fazer, aprendi a significação da ação... (Id., p.13)
\end{abstract}

Esse modo de entender a leitura o marcou tão profundamente que, mais tarde, quando assume a tarefa de ensinar língua portuguesa no então nível secundário, em escola do Recife, recusa-se a reger-se unicamente pelos ditames da gramática normativa para expor os conhecimentos da língua "à curiosidade dos alunos de maneira dinâmica e viva". Explora os significados de textos de autores consagrados ou dos próprios alunos. "Os alunos não tinham que memorizar mecanicamente a descrição do objeto, mas apreender a sua significação profunda" (Id., p.17)

Ao reconhecer a experiência como fonte de conhecimento, não pretendeu defender que sua emergência pudesse se produzir de forma espontânea ou puramente intuitiva, mas como resultado de reflexão rigorosa e sistemática, portanto, como ato de humano de distanciamento das práticas, em que de forma intencional, visa-se o conhecimento sobre práticas e 0 autoconhecimento, mesmo que não necessariamente pretendido.

\title{
3 Relação entre o educador e os movimentos populares
}

Por fim, passemos a um olhar sobre as relações educador/a e os movimentos sociais através de um trecho de vídeo documentário. Trata-se de uma fala de Freire em conversa com Pedro Pontual ${ }^{5}$. A fala provocativa pontua o papel do educador progressista.

Uma das tarefas do educador progressista, hoje, com relação aos movimentos populares é, exatamente, aprendendo com eles, com os movimentos populares, ensinar também. Não há

${ }^{5}$ Educador brasileiro e militante dos movimentos sociais que foi Presidente do CEAAL (Conselho de Educação de Adultos da América Latina, cuja sede situa-se em Santiago do Chile). 
porque temer, quem tenha o dever, a tarefa e o direito de ensinar aos movimentos populares. De jeito nenhum, eu jamais me entregaria, prometendo ser discípulo deles. De jeito nenhum, porque é mentira e é falso. Também não serei o eterno professor de movimentos. Sou um educando educador" (Depoimento de Freire cedido em 1989. IN INSTITUTO PAULO FREIRE. Paulo Freire Contemporâneo, documentário, 2006).

Com a demonização de toda forma de representação, com toda forma de mediação político social, que vem de par com o crescente encantamento com a forma direta de representação política do cidadão para efetivação da democracia, propor um papel para o/a educador/a, na sua relação como os movimentos populares, parece ser uma heresia. Esse debate é, no entanto, mais que oportuno, porque ele agrega questões fundamentais para a construção mesma da democracia como valor e prática social. Vale lembrar que Freire fez essa advertência, mas, antes de tudo, celebrou as tantas marchas que os movimentos sociais produziram e produzem, em favor de questões fundamentais para os excluídos desse país, bem como propôs outras tantas, na medida em que reconhecia o quanto se tem a fazer para que as necessárias transformações ocorram.

De um lado, chama à atenção para a relação entre educador/a e movimentos populares seja de, mutuamente, ensinar e aprender. O que vale dizer, retomando suas palavras, "quem ensina aprende ao ensinar e quem aprende, ensina ao aprender".

Por outro lado, ao recusar ser refém de quem quer que seja, recusa o entendimento dos que querem impingir aos movimentos populares a condição de um oráculo a ser consultado porque nele se situa a Verdade. Rompe assim a ideia de um caminho único que leve à Verdade, advogando sua condição multicêntrica e polifônica. Para isso, impõe-se a necessidade do diálogo, da prática da fala escuta atentiva de quem a ele se integrar e reconhecimento de valor a quem fala e a quem escuta. 


\section{Referências}

ARAÚJO FREIRE, Ana Maria. Paulo Freire. Uma história de vida. S. Paulo: Villa das Letras, 2006.

FREIRE, Paulo. Educação e atualidade brasileira. Recife: Universidade do Recife, 1959.

A importância do ato de ler em três artigos que se completam. S. Paulo: Cortez Editora/Editora Autores Associados, 1982.

Pedagogia da esperança: um reencontro com a Pedagogia do Oprimido. S.

Paulo: Paz e Terra, 1992.

INSTITUTO PAULO FREIRE. Paulo Freire Contemporâneo. S. Paulo, 2006, (documentário).

PAVAN, Ruth. A contribuição de Paulo Freire para a educação popular: uma análise do GT de Educação Popular da Anped. Caxambu: Anais da $31^{\text {a }}$ Reunião Anual, 2008.

MAINGUENEAU, Dominique. Présentation. In: Langages, 29e année, n. 117, 1995. Les analyses du discours en France, sous la direction de Dominique Maingueneau. 